\title{
Suspension Dry Spinning and Rheological Behavior of Ceramic-Powder-Loaded Polymer Solutions
}

\author{
S. D. Nunn,,$^{*, \dagger}$ D. Popovic,,$^{\star, \dagger}$ S. Baskaran, ${ }^{*, \dagger}$ J. W. Halloran, ${ }^{*, \dagger}$ G. Subramanian, ${ }^{\ddagger}$ and S. G. Bike ${ }^{\ddagger}$ \\ Department of Chemical Engineering and Department of Materials Science and Engineering, \\ University of Michigan, Ann Arbor, Michigan 48109
}

\begin{abstract}
Green ceramic fibers of $\mathrm{Al}_{2} \mathrm{O}_{3}, \mathrm{Si}_{3} \mathrm{~N}_{4}, \mathrm{Ce}-\mathrm{ZrO}_{2}$, and $\mathrm{SiC}$ were prepared by suspension dry spinning of powderloaded polymer solutions. The fiber-forming polymer was ethyl methacrylate dissolved in methyl ethyl ketone. The experimental conditions for fiber formation were defined for the alumina system. Thread lengths measured as a function of extrusion rate showed a transition from capillary-limited fracture to continuous fibers in agreement with Ziabicki's theory of thread formation. The conditions for spinnability were correlated to rheological parameters. Spinnable $\mathrm{Al}_{2} \mathrm{O}_{3}$ dopes were elastic fluids with a high viscosity $\left(60 \mathrm{~Pa} \cdot \mathrm{s}\right.$ at $\left.0.46 \mathrm{~s}^{-1}\right)$ under the conditions of this study.
\end{abstract}

\section{Introduction}

$\mathrm{C}$ ERAMIC fibers are frequently prepared by sintering "green fibers" consisting of polymers loaded with ceramic powders. Green fibers have been prepared by extrusion of molten polymer-powder blends (melt spinning) ${ }^{1-5}$ and by extrusion of a suspension of powder in a polymer solution either into a coagulating bath (wet spinning) ${ }^{6}$ or into a drying column (dry spinning). ${ }^{79}$ In this paper, we describe a simple dry spinning process for green ceramic fibers. We have used this system to prepare alumina, silicon nitride, Ce-zirconia, and silicon carbide fibers. We use these green fibers to fabricate monolithic ceramics with fibrous microstructures. ${ }^{10,11}$ In this paper, we have also defined the composition and extrusion conditions for spinnability of one system, the alumina-powder-loaded polymer solutions, and related this to their theological behavior. The extrusion behavior of the other ceramic-powder-loaded polymer solutions systems as a function of composition were qualitatively similar, and so were not studied in detail.

\section{Experimental Procedure}

Ceramic-filled fibers containing 54 to 64 vol\% ceramic phase were prepared from mixtures ("dopes") of ceramic powders suspended in a polymer solution. The ceramic powders included $\mathrm{Al}_{2} \mathrm{O}_{3}$ (RC-HP DBM, Reynolds Metal Co., Richmond, VA), $\mathrm{Si}_{3} \mathrm{~N}_{4}$ (UBE-E10, UBE Industries, Inc., New York, NY), $\mathrm{SiC}$ (Grade B-10, H. C. Starck, Berlin, Germany), and Ce-ZrO (TZ-12CE, Tosoh Ceramics Division, Bridgewater, NJ). The fiber-forming polymer was an ethyl methacrylate copolymer (EMA) (Acryloid B-7 MEK, Rohm and Haas, Philadelphia, PA) dissolved in methyl ethyl ketone (MEK). Characterization using gel-permeation chromatography indicated that the number-average molecular weight was $\approx 91000$ dalton and the

R. Bordia- contributing editor

Manuscript No. 194799. Received March 8, 1993; approved June 18, 1993.

Supported by DARPA and the Office of Naval Research under Contract No. N0014-91-J-1999.

"Member, American Ceramic Society.

Department of Materials Science and Engineering.

Department of Chemical Engineering. weight-average molecular weight was $\approx 124000$ dalton. The starting ceramic powders were mixed with MEK and dispersants (Span 85, ICI Americas, Inc., Wilmington, DE; Emphos PS-21A, Witco, New York, NY) and ball-milled using alumina milling media in a polyethylene jar. After milling for $18 \mathrm{~h}$, one quarter of the polymer solution was added to the milling jar and this mixture was milled for another $12 \mathrm{~h}$. The remaining polymer solution was then added and the mixture milled for a final 18-h period. The final mixture contained approximately 14 to 29 vol\% solids (ceramic plus polymer).

After ball milling, some of the MEK solvent was evaporated to leave experimental dopes with solids contents from 28.7 to $61.3 \mathrm{vol} \%$, corresponding to MEK solvent levels of $71.3 \mathrm{vol} \%$ for the most dilute dopes to $38.7 \mathrm{vol} \%$ for the most concentrated. These were used for rheological characterization and evaluation of "spinnability" by extrusion into a drying column.

The spinning apparatus was very simple, consisting of a hypodermic syringe fitted with a 0.33 -mm-diameter ( 23 gauge) needle, shortened to $10 \mathrm{~mm}$ by grinding on abrasive paper. The syringe was filled with the spinning dope and then sealed with a pneumatic adapter head. Gas pressure up to $0.52 \mathrm{MPa}$ (75 psi) was applied to extrude the dope into a 1.8 -m high drying column heated to $105^{\circ} \mathrm{C}$. The maximum pressure possible in the plastic syringe without bulging was $0.59 \mathrm{MPa}$ ( $85 \mathrm{psi}$ ). The dryspun fiber was collected at the bottom of the hot air column.

The rheological behavior of the dopes was characterized using a Bohlin rheometer (Bohlin VOR rheometer, Cranbury, $\mathrm{NJ})$ operating in both oscillatory strain mode and steady shear mode using either concentric cylinder or cone-and-plate geometry. The oscillatory measurements were done over a range of strain amplitudes $(0.0002$ to 0.1$)$ and frequencies $(0.03$ to $9 \mathrm{~Hz})$. A solvent trap was used to prevent loss of the volatile MEK, so that stable and repeatable measurements could be made over several hours. The sample temperature was controlled to $25 \pm 0.1^{\circ} \mathrm{C}$.

\section{Results and Discussion}

Figure 1(A) shows a typical alumina green fiber produced by extruding a dope through a $300-\mu \mathrm{m}$ orifice. The dry-fiber diameter is about $150 \mu \mathrm{m}$ in this case, reflecting size reduction due to self-drawing of the wet extrudate, as well as drying shrinkage. A more circular fiber cross section is typical of more concentrated dopes. Dopes with higher solvent content usually produced figure-eight or kidney-shaped cross sections. Figure 1(B) is a high-magnification view of a fiber showing the $0.5-\mu \mathrm{m}$ alumina particles and EMA polymer. This is a typical dry-fiber microstructure of the $60 \mathrm{vol} \%$ ceramic $-40 \mathrm{vol} \%$ polymer composition in the bulk of the fiber. The surfaces of the fiber are more saturated with the polymer presumably due to polymer migration with the solvent to the surface. These fibers are produced at rates of $45-150 \mathrm{~m} / \mathrm{min}$ at lengths up to $300 \mathrm{~m}$ with diameters in the range of $100-150 \mu \mathrm{m}$.

The $60 \mathrm{vol} \%$ ceramic dry fiber composition produces a flexible fiber for all the powders that we have examined. Polymer concentration can be decreased at least up to $85 \mathrm{vol} \%$ ceramic, although these produce brittle green fibers. Higher polymer concentration improves green strength, flexibility, and spinnability, although at the cost of the subsequent sinterability of the 

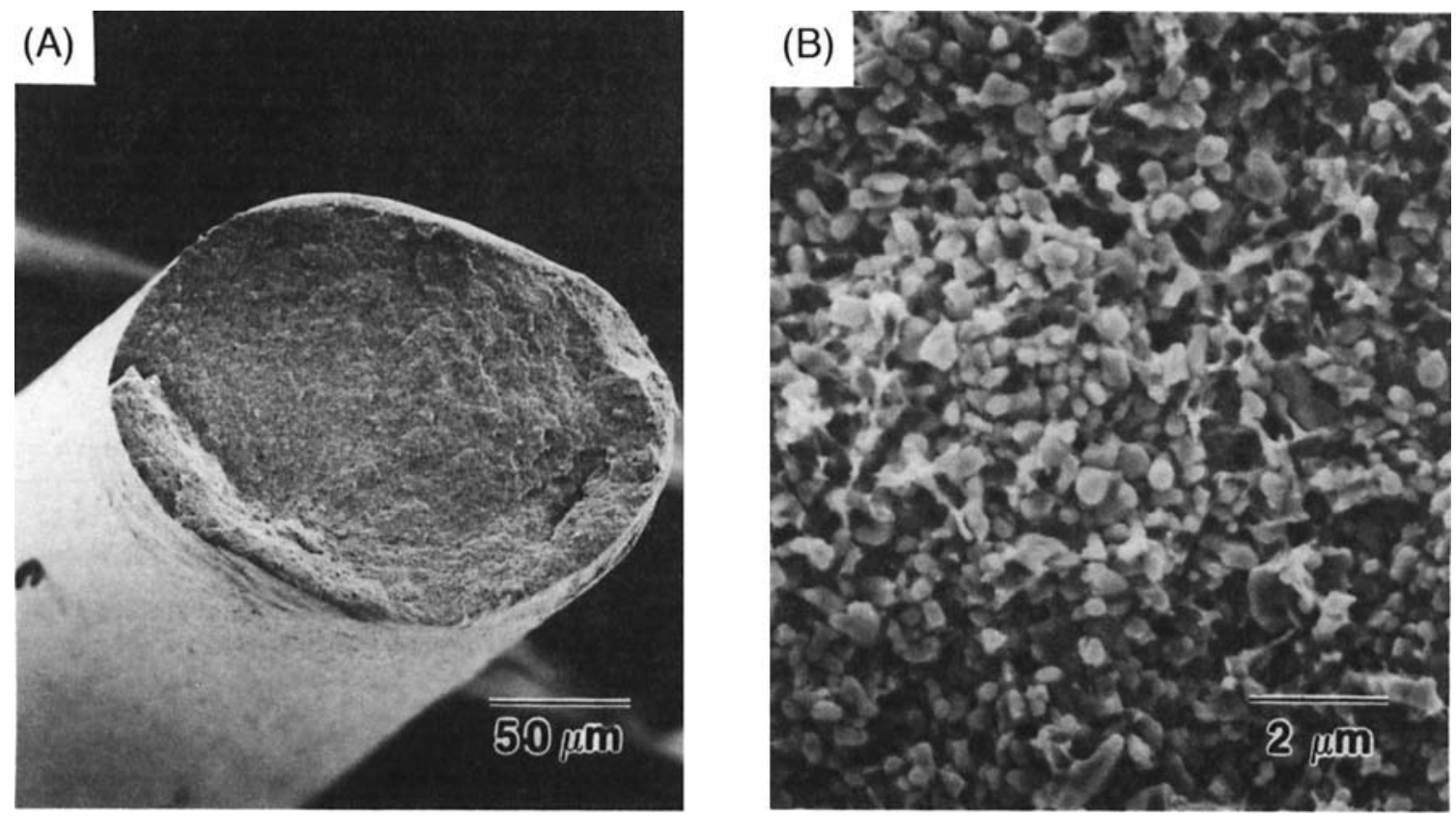

Fig. 1. SEM micrographs showing (A) alumina green fiber and (B) alumina particles in a matrix of ethyl methacrylate polymer.

fiber. For most powders, fibers are sinterable at 50 vol\% ceramic, although green fibers from highly sinterable zirconia powders are sinterable at 45 vol\% ceramic.

Table I lists several spinnable dope compositions yielding 60 vol\% ceramic dry fibers. This simple system is very useful for a wide variety of powders, with specific surface areas between 7.6 and $15.6 \mathrm{~m}^{2} / \mathrm{g}$, and surface acidities from acidic $\mathrm{SiC}$ (aqueous isoelectric point (IEP) at $\mathrm{pH} 3)^{12}$ to basic $\mathrm{Si}_{3} \mathrm{~N}_{4}$ (IEP at $\mathrm{pH}$ 10).${ }^{13}$ In spite of the difference in powder surface chemistry, we find it convenient to use the same dispersants for all powders, typically $1.0 \mathrm{wt} \%$ dry basis of phosphate ester (Emphos PS-21A, Witco Corp., New York, NY) and 0.3 wt\% sorbitan trioleate (Span 85, ICI, Wilmington, DE). Clearly, this concentration is not optimal for all powders. Silicon carbide dopes tend to be more viscous, while Ce-zirconia dopes are more fluid, but all can be extruded into fibers. The simple systems we have studied do not employ a plasticizer, so the fibers embrittle once the solvent is fully lost, several days after spinning. Standard plasticizers such as dioctyl phthalate can be incorporated to maintain flexibility.

\section{(1) Fiber Spinning of Alumina Dopes}

Experiments on the spinning behavior have been performed using an alumina spinning dope formulated to give a dry fiber $60 \mathrm{vol} \%$ alumina $-40 \mathrm{vol} \%$ polymer. The spinning dope composition is a ternary system consisting of the ceramic powder, the ethyl methacrylate polymer, and the MEK solvent, as shown in Fig. 2. The compositions are reckoned as follows: the " 35.7 vol\% solids" composition refers to a mixture of 64.3 vol\% MEK with $35.7 \mathrm{vol} \%$ of a dry solid consisting of $60 \mathrm{vol} \%$ alumina-40 vol\% EMA. The dope itself consists of alumina particles suspended in MEK containing 18.2 vol\% dissolved EMA. The more concentrated 49.8 vol\% total solids dope consists of alumina powder in MEK containing 28.4 vol\% dissolved EMA.
As a practical matter, if the spinning dope had too much MEK (too low of a viscosity), either the extrudate from the spinneret would fragment because of capillary instability or the fiber would not be dry when it reached the bottom of the drying column. If the viscosity of the dope was too high, the dope would not extrude through the spinneret at the maximum pressure $(0.59 \mathrm{MPa}(85 \mathrm{psi}))$ possible with this apparatus. These factors narrowed the region of fiber spinnability in this system.

When the polymer solution is loaded with sufficient ceramic powder, the weight of the fiber in the drying column is enough to make it self-drawing from the spinneret, thus forming a fiber by gravity feed. The neat polymer, however, was of such low density that it would require mechanical drawing from the spinneret, for instance by a take-up drive, to obtain a fiber. With this simple spinning apparatus, we were limited to compositions dense enough to be self-drawing. Only compositions containing more than 50 vol\% ceramic in the dry fiber are of technological interest.

We have assessed the spinnability of the alumina dope as a function of the MEK solvent concentration. Dopes at 28.7 and 32.3 vol\% solids were not spinnable. These dopes quickly formed drops after extrusion, and fibers did not form. Dopes at $35.7,39.5$, and $49.8 \mathrm{vol} \%$ solids were fiber forming. The dope at 61.3 vol\% solids was too viscous to be extruded at the 0.59-MPa pressure limit of our equipment.

The fiber cross section at 35.7 vol\% solids is kidney-shaped. The equivalent fiber diameter depended upon pressure, increasing from $60 \mu \mathrm{m}$ at the low pressure limit to $135 \mu \mathrm{m}$ at the highest pressure. The nonuniform cross section occurs when the fiber surface dries too rapidly as it emerges from the spinneret into the drying column, forming a more rigid skin. Upon further evaporation of the solvent, the skin collapses in forming a kidney-shaped fiber. For the more concentrated dopes at 39.5 and 49.8 vol\% solids, the fiber cross section is circular to slightly

Table I. Representative Spinnable Dopes for Green Fibers at 50 vol\% Ceramic Dry Composition

\begin{tabular}{lclcccc}
\hline Powder & $\begin{array}{c}\text { Specific } \\
\text { surface area } \\
\left(\mathrm{m}^{2} / \mathrm{g}\right)\end{array}$ & $\begin{array}{c}\text { Surface } \\
\text { acidity }\end{array}$ & $\begin{array}{c}\text { Ceramic } \\
(\mathrm{wt} \%)\end{array}$ & $\begin{array}{c}\text { Polymer } \\
\text { EMA } \\
(\mathrm{w} t \%)\end{array}$ & $\begin{array}{c}\text { Solvent } \\
\text { MEK } \\
(\mathrm{wt} \%)\end{array}$ & $\begin{array}{c}\text { Surfactant } \\
(\mathrm{wt} \%)\end{array}$ \\
\hline $\mathrm{Al}_{2} \mathrm{O}_{3}$ & 7.6 & Slightly basic & 58.5 & 11.5 & 29.2 & 0.8 \\
$\mathrm{SiC}$ & 15.6 & Acidic & 56.2 & 13.8 & 29.2 & 0.8 \\
$\mathrm{Si}_{3} \mathrm{~N}_{4}$ & 10 & Basic & 56.2 & 13.9 & 29.2 & 0.8 \\
$\mathrm{Ce}_{4}-\mathrm{ZrO}_{2}$ & 9.4 & Basic & 62.1 & 7.91 & 29.2 & 0.8 \\
\hline
\end{tabular}




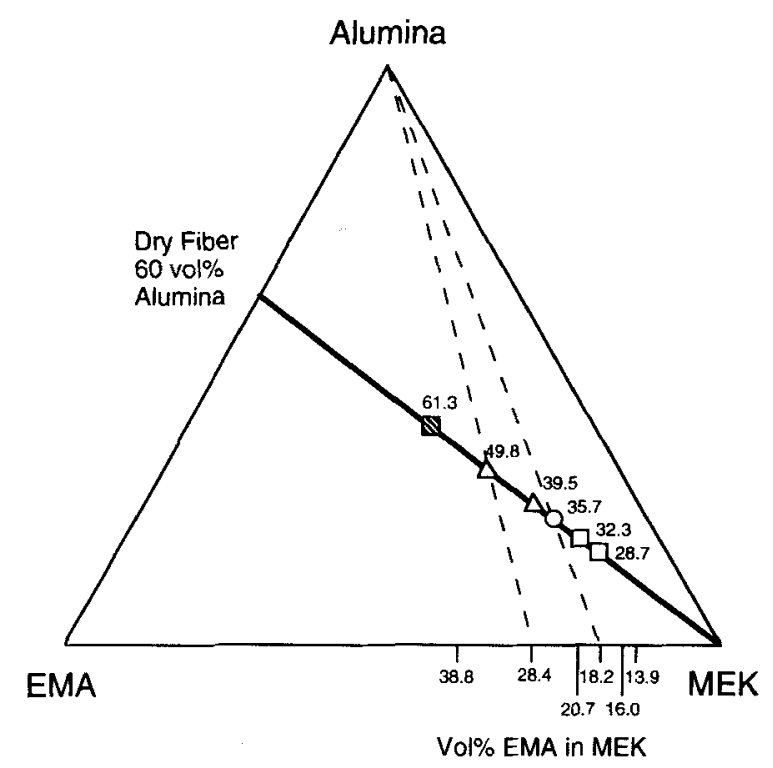

$\square \quad$ No Thread Formed
$\bigcirc \quad$ Short Threads
$\triangle \quad$ Continuous Fiber
Too Viscous To Be Extruded

Fig. 2. Diagram showing alumina dope compositions with respect to volume fraction of components. Numbers next to symbols refer to vol\% solids (alumina + ethyl methacrylate) in MEK.

oval, and mean fiber diameters (100 and $110 \mu \mathrm{m}$ for 39.5 and 49.8 vol\% solids, respectively) are independent of the extrusion pressure.

We present our observations on spinnability in the context of the Ziabicki ${ }^{14}$ theory of fiber formation which describes the onset of spinnability. Ziabicki suggests that the tendency for fiber formation can be measured by the length of fluid threads produced before the fibers break. Fiber breakup can occur either by capillary effects or by elastic effects. Both depend upon the fiber velocity, dope viscosity, and relaxation time. Figure 3 shows schematically how the fiber length for a Maxwell viscoelastic fluid is affected by $\eta V$, the product of viscosity of the spinning dope $[\eta]$ and the extrusion velocity of the fiber $[V]$. At lower values of the $\eta V$ parameter, fibers can undergo capillary breakup due to unstable oscillations associated with surface tension. Thread length should increase with viscosity in this regime. For higher values of the $\eta V$ parameter, fibers undergo cohesive fracture when the unrelaxed tensile stress from fiber elongation reaches the tensile strength of the fluid. In this regime, thread length should decrease at high velocities and long relaxation times. Since the relaxation time increases with viscosity, thread length should decrease with the $\eta V$ parameter. Once the thread length exceeds the solidification length for the fluid (by drying in this case), continuous fibers are produced. This is illustrated in Fig. 3, as the "more spinnable" fluid produces continuous fibers in a range of $\eta V$ where the fiber length exceeds the solidification length.

Experimental results of fiber length versus the product of viscosity and velocity were collected by directly measuring the length of short fibers, or threads, obtained as a function of extrusion pressure. The viscosity-velocity $[\eta V]$ product was obtained from the extrusion pressure and orifice radius $[R]$ and length $[L]$, using the Hagen-Poiseuille equation: $\eta V=\left[R^{2}\right]$ $8 L] \Delta P$. The less spinnable dopes produced short threads with a wide distribution of lengths. Several hundred threads were measured under each condition to define the statistics of the thread
Fiber Length - Ziabicki Theory

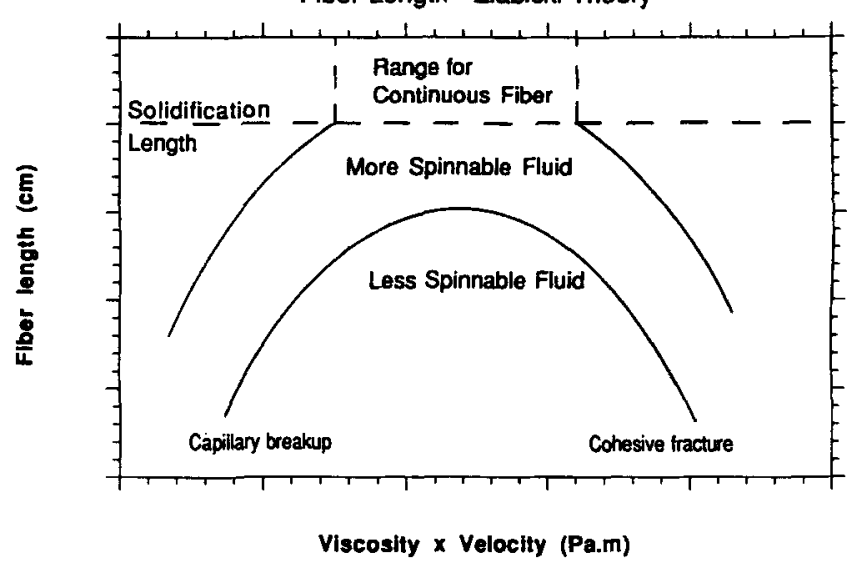

Fig. 3. Schematic showing dependence of fiber length on the product of dope viscosity $(\eta)$ and extrusion velocity $(V)$ for a viscoelastic fluid.

lengths. Figures $4(\mathrm{~A}-\mathrm{C})$ present the distribution of thread lengths for all three spinnable dopes. In these plots, the lower lines represent the thread length at the 25 percentile, the middle lines are the median thread lengths, and top lines represent the 75 percentile. Therefore, $50 \%$ of the fibers have lengths that lie in the shaded regions.

The dope at 35.7 vol\% solids formed fibers of finite length at all accessible values of $\eta V$ product. Fiber length increased with $\eta V$, but the data are too scattered to determine if it reached a maximum at higher values. The more concentrated dope at 39.5 vol\% solids showed transition from finite-length fibers at $\eta V$ values below $0.12 \mathrm{~Pa} \cdot \mathrm{m}$, where the threads were presumably capillary-limited, to continuous fibers at higher $\eta V$ values. Continuous fibers indicate that the threads were longer than the solidification length in the drying column. An elastic-limited decrease in thread length did not occur up to the maximum pressure of our apparatus. With the dopes containing $49.8 \mathrm{vol} \%$ solids, fibers were continuous over the whole pressure range possible with our apparatus.

The transition from capillary-limited fracture at low $\eta V$ (i.e., low $\Delta P$ ) to continuous fibers at high $\eta V$ (high $\Delta P$ ) has also been observed for EMA/MEK solutions loaded with specific concentrations of $\mathrm{SiC}$ or $\mathrm{Ce}-\mathrm{ZrO}_{2}$ powders. For $\mathrm{SiC}$ dopes with 43- 44 vol\% solids content, we find that on increasing the pressure from $30 \mathrm{psi}(0.21 \mathrm{MPa})$ to $70 \mathrm{psi}(0.52 \mathrm{MPa})$, the extrusion product changes from discontinuous threads to continuous fiber. Zirconia dopes behave similarly. Since extrusion behavior versus $\eta V$ are qualitatively similar for suspensions prepared from three quite different ceramic powders $\left(\mathrm{Al}_{2} \mathrm{O}_{3}, \mathrm{SiC}\right.$, and $\mathrm{Ce}-\mathrm{ZrO}_{2}$ ), we believe that the interpretation of spinnability in terms of Ziabicki's theory may be generally applicable for ceramic systems dry spun from polymer solutions.

\section{(2) Rheology Measurements}

We performed a series of viscometry experiments to examine how the practical spinnability of the alumina dopes is related to their rheological behavior in shear. The highest shear rate accessible was $1000 \mathrm{~s}^{-1}$, which is much lower than the shear rate experienced by the dope during extrusion through the spinneret. The shear rate during extrusion and effective dope viscosity can be estimated from the volumetric flow rate, $Q$, at any pressure $\Delta P$, i.e., by using the fiber extrusion apparatus as a crude capillary viscometer. Using the Hagen-Poiseuille equation, one can estimate an effective viscosity of $\left[\pi R^{4} \Delta P\right] /[8 L Q]$ and a shear rate of $\left[4 Q / \pi R^{3}\right] . L$ and $R$ are the length and inner radius of the syringe needle.

The results of rheological measurements are shown in Figs. 5 and 6 . Figure 5 presents values of the viscosity as a function of shear rate, obtained for dopes of various volume fraction of solids. The dopes are shear thinning, but the behavior cannot be represented by a simple power law. Instead, the Cross model ${ }^{15}$ 

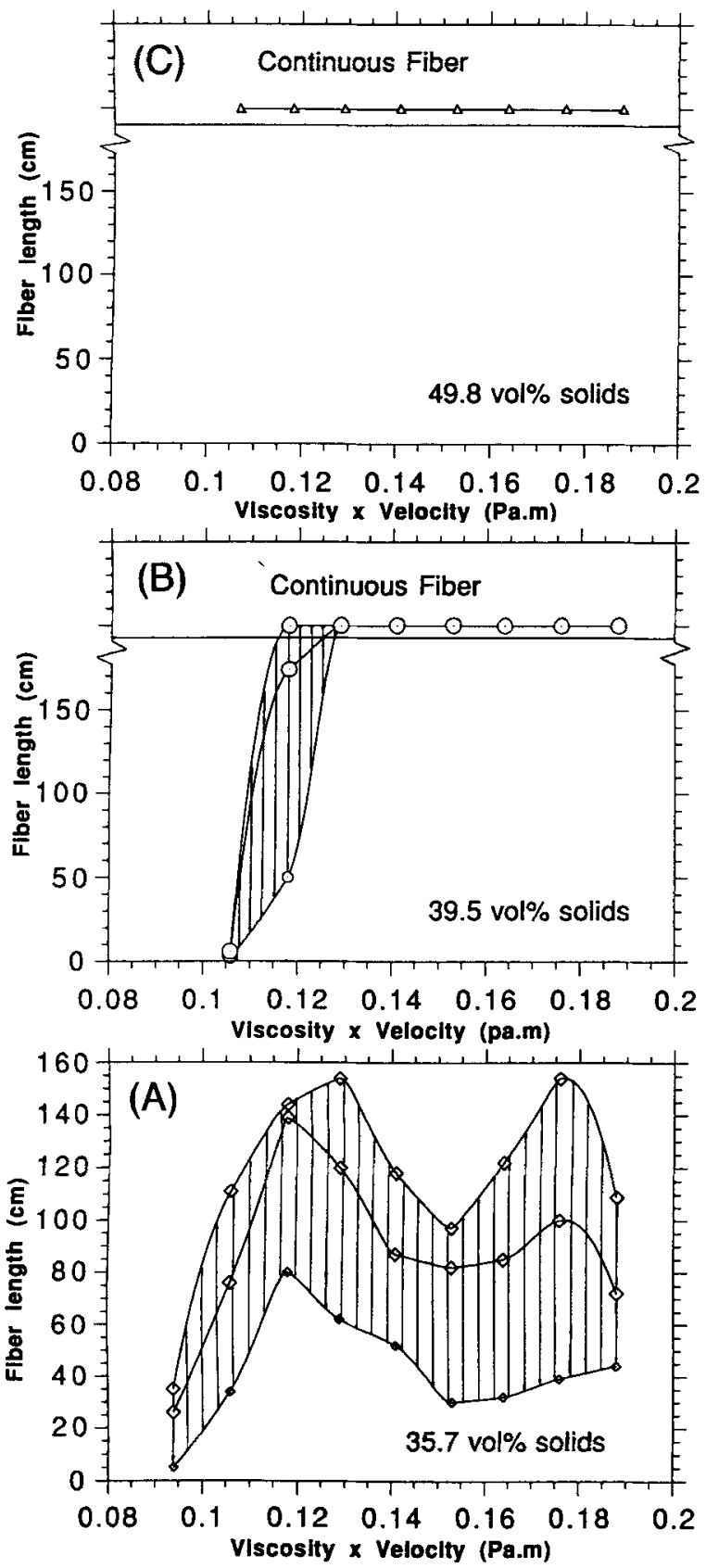

Fig. 4. Distribution of fiber lengths as a function of $\eta V$ for alumina dopes with (A) 35.7, (B) 39.5, and (C) 49.8 vol\% solids.

can be empirically fitted to the data (excluding those data at shear rate $>1000 \mathrm{~s}^{-1}$ ) as shown in Fig. 5. This model describes both the low and high shear Newtonian plateaus as well as the shear thinning at intermediate shear rates. The parameters obtained by fitting the model to the data are listed in Table II.

The points at high shear rates $\left(>1000 \mathrm{~s}^{-1}\right)$ in Fig. 5 are the apparent viscosities and shear rates calculated from the extrusion rates during fiber spinning. The calculation of the apparent viscosity from the extrusion data is subject to errors due to the elastic nature of the dopes, and due to the exit and entrance effects on the flow for short tube length to diameter ratios. We find that the approximate capillary viscosities are in reasonably good agreement with the shear viscosities. Note that we have not characterized the rheological behavior under the elongational flow conditions that occurs during self-drawing after extrusion. We have simply attempted to correlate the rheological state in shear measured in the viscometer with the behavior of the fluid under extrusion conditions.

The viscosity at a shear rate of $0.46 \mathrm{~s}^{-1}$ as a function of dope concentration is shown in Fig. 6(A). The shear rate of $0.46 \mathrm{~s}^{-1}$

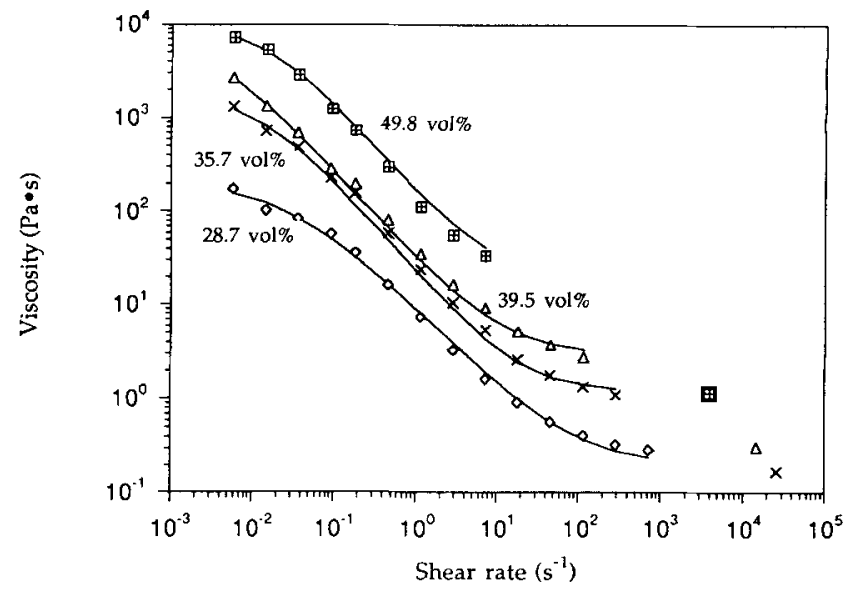

Fig. 5. Viscosity as a function of shear rate for dopes of various volume fractions of solids. Solid lines indicate Cross model fitted to the data points. The data points at high shear rates $\left(>1000 \mathrm{~s}^{-1}\right)$ were calculated from extrusion data.

was approximately in the middle of the shear rate range used in this study. As expected, the viscosity increases strongly at higher loadings of solids, due to the increase in polymer concentration in the suspending medium and the increase in suspended powder loading. Measurements could not be made with the $61.3 \mathrm{vol} \%$ dope because of the high viscosity, and because of drying of the sample even with the solvent trap. The viscosities for the neat polymer solutions corresponding to the various
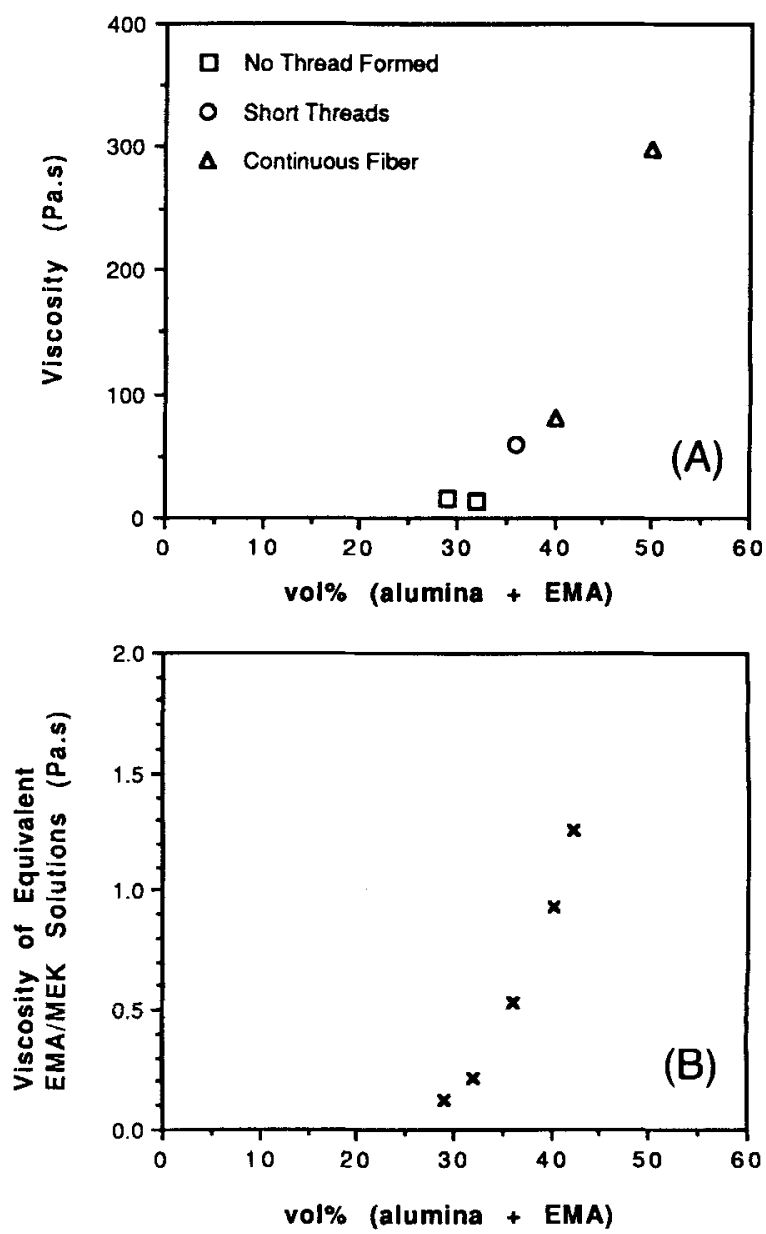

Fig. 6. Viscosity as a function of dope solids content at a shear rate of $0.46 \mathrm{~s}^{-1}$ for (A) alumina fiber-spinning dopes and (B) polymer solutions corresponding to the dope formulations. 
Table II. Cross Model Parameters for Viscosity Dependence on Shear Rate of Alumina Fiber Spinning Dopes

$$
\frac{\eta-\eta_{\infty}}{\eta_{0}-\eta_{x}}=\frac{1}{1+(K \gamma)^{m}}
$$

\begin{tabular}{|c|c|c|c|c|}
\hline $\begin{array}{l}\text { Solids } \\
\text { content } \\
\text { (vol\%) }\end{array}$ & $\begin{array}{c}\eta_{n_{0}}{ }^{(a)} \\
\mathrm{Pa} \cdot \mathrm{s})\end{array}$ & $\begin{array}{c}\eta_{x_{x}}{ }^{7} \\
(\mathrm{~Pa} \cdot \mathbf{s})\end{array}$ & $\begin{array}{l}K^{\S} \\
(\mathrm{s})\end{array}$ & $m^{\natural}$ \\
\hline 28.7 & 200 & 0.2 & 39 & 0.84 \\
\hline 35.7 & 1800 & 1.2 & 80 & 1.0 \\
\hline 39.5 & 7500 & 3 & 327 & 0.95 \\
\hline 49.8 & 10000 & 20 & 65 & 1.0 \\
\hline
\end{tabular}

${ }^{\prime}$ Zero shear viscosity. ${ }^{\prime} \mathrm{High}$ shear viscosity. "Shear rate coefficient. "Shear rate exponent.

dope formulations are shown in Fig. 6(B). The stock EMA/ MEK solution was supplied at $30 \mathrm{wt} \%$, equivalent to the polymer solution present in $a \approx 42$ vol\% fiber-spinning dope. Evaporation of a small amount of MEK from this solution resulted in gelation, so the viscosity of the polymer solution corresponding to the higher solids dope ( $49.8 \mathrm{vol} \%$ ) could not be measured. It is useful to note, however, that the alumina-containing dope concentrated to $50 \mathrm{vol} \%$ solids had not gelled in spite of the high polymer concentration. This can be attributed to a decrease in the polymer concentration in the suspension medium due to adsorption on the alumina powder surfaces.

The addition of the submicrometer alumina powder (and dispersant) results in the formation of a colloidal network and an increase in viscosity by a factor of $\approx 100$ over the corresponding polymer solutions, for the whole range of solids loading from 29 to 40 vol\%. Note that dispersants were not optimally selected, which would indicate that more effective dispersion should result in low-viscosity "spinnable" dopes with higher solids content. The influence of dispersant concentration on rheological behavior of this system is reported elsewhere. ${ }^{16}$ The dopes with low solids content (28.7 and 32.3 vol\%) and low viscosity were not spinnable. The onset of spinnability corresponded to a viscosity of $\approx 60 \mathrm{~Pa} \cdot \mathrm{s}$ at $0.46 \mathrm{~s}^{-1}$.

Shear moduli measurements were made in both the linear and nonlinear viscoelastic regions. The complex shear modulus $G^{*}$ $\left[=G^{\prime}+i G^{\prime \prime}\right]$ was separated into the real part, or storage modulus $G^{\prime}$, which describes the elastic behavior of the dope, and the imaginary part, or loss modulus $G^{\prime \prime}$, which describes the viscous behavior.

Figure 7 summarizes the data from the oscillation experiments as a plot of loss tangent $\left(G^{\prime \prime} / G^{\prime}\right)$ versus volume fraction of solids in the dope at a frequency of $1 \mathrm{~Hz}$. For measurements

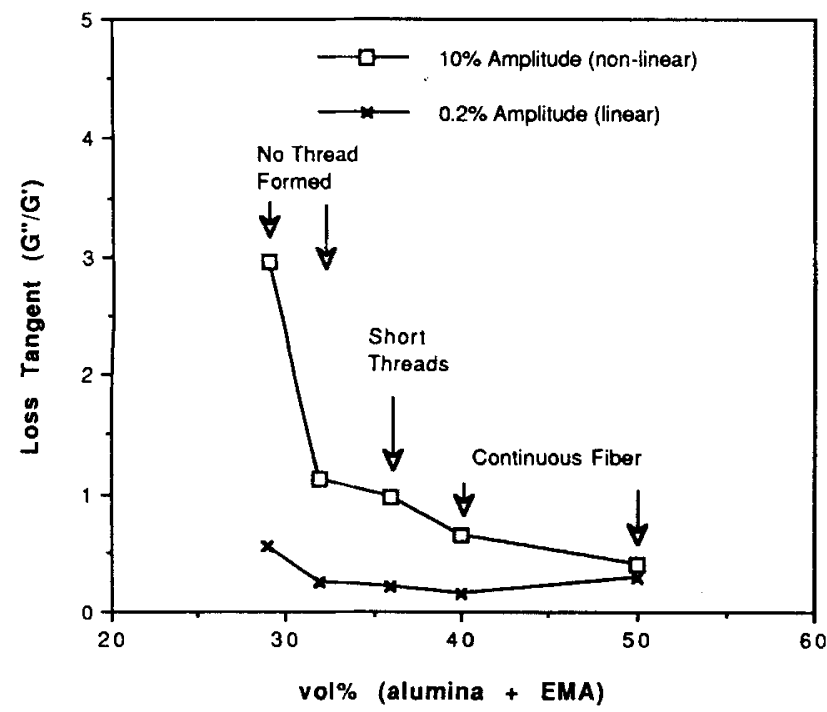

Fig. 7. Loss tangent as a function of solids content for alumina fiber spinning dopes. made in the linear viscoelastic regime at $0.2 \%$ amplitude (strain of 0.0004$)$, the low $(<1)$ loss tangents indicate the elastic nature of the network structure. $G^{\prime}$ and $G^{\prime \prime}$ increase with solids content, and the loss tangent values indicate the relative increase. Other investigators ${ }^{17}$ have observed a dramatic decrease in loss tangent for fiber-forming sols at the onset of spinnability using specific measuring conditions. We find that the boundary between spinnable and nonspinnable fluids does not correspond to any specific value of $\tan \delta$, and that there is no significant change in $\tan \delta$ at the onset of spinnability when measurements are made in the linear regime. For oscillation measurements in the high-amplitude nonlinear region at $10 \%$ amplitude (strain of 0.02 ), we find that the loss tangent decreases significantly and observe that $\tan \delta \approx 1$ at the onset of spinnability. However, $G^{\prime}$ and $G^{\prime \prime}$ are both amplitude and frequency dependent, and moduli measurements from oscillation experiments are meaningful only if made in the linear viscoelastic regime. A loss tangent of unity at the onset of spinnability is simply an artifact of the measuring conditions in the nonlinear regime. We conclude that exact values of loss tangent cannot be correlated to spinnability.

\section{Conclusions}

Continuous green fibers of $\mathrm{Al}_{2} \mathrm{O}_{3}, \mathrm{SiC}, \mathrm{Si}_{3} \mathrm{~N}_{4}$, and $\mathrm{Ce}-\mathrm{ZrO}_{2}$ powder suspended in an ethyl methacrylate polymer binder were produced by suspension dry spinning. The conditions of spinnability were examined in the $\mathrm{Al}_{2} \mathrm{O}_{3}$ system. Alumina dopes were not spinnable at 32.3 vol\% solids [ceramic + polymer], marginally spinnable at 35.7 vol\% solids, and continuously spinnable above 39.5 vol\% solids. The onset of spinnability with increasing extrusion rate for low solids dopes was interpreted as a transition from capillary breakup to continuous fibers. Rheological measurements showed that the high solids spinnable dopes have a high viscosity and significant elastic character.

\section{References}

'S. Suemura, "Ceramic Fibers and the Manufacturing Method Thereof," Japanese Kokai Pat. No. SHO 63-190022, August 5, 1988.

${ }^{2}$ I. W. Halloran, V. Pathare, G. Bakis, and D. Eagles, "Fabrication and Properties of Ceramic Fibers by the Green Fiber Method"; presented at the 92 nd Annual Meeting of the American Ceramic Society, Dallas, TX, April 23, 1990 (Paper No. 1-SIV-90)

'F. Frechette, B. Dover, V. Venkateswaran, and J. Kim, "High Temperature Continuous Sintered SiC Fiber for Composite Applications," Ceram. Eng. Sci. Proc., 12 [7-8] 992-1006 (1991).

${ }^{4}$ F. Frechette, W. D. Boecker, and C. H. McMurtry, "Non-oxide Sintered Ceramic Fibers," U.S. Pat. No. 4908340 , March 13, 1990.

${ }^{5}$ J. W. Halloran, J. Hodge, D. Chandler, L. J. Klemptner, M. Neal, M. Parish, H. Park, and V. Pathare, "Fabrication and Properties of High Temperature Superconducting Wire by the Green Fiber Method,"J. Am. Ceram. Soc., 75 [4] 903-907 (1992).

${ }^{6}$ R. B. Cass, "Fabrication of Continuous Ceramic Fiber by the Viscose Suspension Spinning Process," Am. Ceram. Soc. Bull., 70 [3] 424-29 (1991).

'P. Bracke, H. Schurmans, and J. Verhoest, Inorganic Fibres and Composite Materials-A Survey of Recent Developments, European Patent Office, EPO Applied Technology Series, Vol. 3. Pergamon Press, New York, 1984.

${ }^{8}$ See the Du Pont patents on dry spinning an aqueous mix of alumina powder and precursors; U.S. 3953561,3853688 and 3808015

${ }^{9}$ L. D. Hart and A. Pearson, "Production of Continuous Ceramic Fibers: Polyethylene Oxide Polymers," U.S. Pat. No. 4071 594, January 31, 1978.

"W. S. Coblenz, "Fibrous Monolithic Ceramic and Method for Production," U.S. Pat. No. 4772524, September 20, 1988

"S. Baskaran, S. D. Nunn, D. Popovic, and J. W. Halloran, "Fibrous Monolithic Ceramics: I, Fabrication, Microstructure, and Indentation Behavior," J. Am. Ceram. Soc., 76 [9] 2209-16 (1993).

${ }^{12}$ M. J. Crimp, R. E. Johnson, Jr., J. W. Halloran, and D. L. Feke, "Colloidal Behavior of Silicon Carbide"; Ch. 56 in Ultrastructure Processing of Ceramics, Glasses, and Composites. Edited by L. L. Hench and D. R. Ulrich. Wiley, New York, 1986.

${ }^{13}$ M. J. Crimp; M.S. Thesis. Case Western Reserve University, Cleveland OH, 1985.

${ }^{14} \mathrm{~A}$. Ziabicki, Fundamentals of Fiber Formation; Ch. 2. Wiley-Interscience, New York, 1976.

${ }^{15}$ H. A. Barnes, J. F. Hutton, and K. Walters, An Introduction to Rheology; Ch. 2. Elsevier, New York, 1989.

${ }^{16}$ G. Subramanian, S. G. Bike, S. Baskaran, D. Popovic, and J. W. Halloran, "The Role of Rheological Characterization of Ceramic Dopes in Predicting Fiber Spinning Performance"; in Proceedings of the MRS Symposium on Flow and Microstructure of Dense Suspensions, in press.

${ }^{17}$ M. D. Sacks, C. S. Khadilkar, G. W. Scheiffele, A. V. Shenoy, J. H. Dow, and R. S. Sheu, "Dispersion and Rheology in Ceramic Processing"; pp. 495-515 in Advances in Ceramics, Vol. 21, Ceramic Powder Science. American Ceramic Society, Westerville, OH, 1987. 